\title{
¿QUIÉN PAGA POR LA PAZ EN COLOMBIA?
}

Vanda Felbab-Brown*

Colombia vota el domingo en un plebiscito sobre el histórico acuerdo de paz con la guerrilla izquierdista de las FARC, y gran parte de la conversación en ese país se ha centrado en quién se beneficia con la paz. Aunque el pacto de paz ofrece una oportunidad sin precedentes para poner fin a un factor significativo de la violencia civil que dura ya varias décadas, muchos colombianos creen que las FARC se benefician mucho más que el pueblo colombiano y son ambivalentes ante el acuerdo. Si el plebiscito no aprobase el acuerdo, los costos para el país serían enormes. El gobierno carece de un plan в у se podría perder una oportunidad que tiene pocas probabilidades de volver a presentarse durante mucho tiempo.

Sin embargo, aun si se aprobase el plebiscito -como es deseablehay que hacer una pregunta clave: ¿quién paga por la paz de Colombia? Esa pregunta incluye los costos monetarios estrictos de implementar los diversos componentes del acuerdo de paz, incluidos el desarme, desmovilización y reintegración (DDR) de los combatientes de las FARC y el desarrollo rural, así como la pregunta más amplia de los costos políticos para los diversos actores colombianos. Este escrito explora los costos políticos de la implementación que habrán de asumir las FARC, las fuerzas armadas, los políticos derechistas, la élite y los intereses creados, las personas desplazadas, los cultivadores de coca y la clase media. El análisis también aborda el papel y el impacto

* Senior Fellow, Foreign Policy, Informe elaborado por el Center for 21st Century Security and Intelligence, 29 de septiembre de 2016. Se publica con las autorizaciones correspondientes. Traducción de Alberto Supelano. Fecha de recepción: 1-10-2016, fecha de aceptación: 20-10-2016. Sugerencia de citación: Felbab-Brown, V. “¿Quién paga por la paz en Colombia?”, Revista de Economía Institucional 18, 35, 2016, pp. 13-38. Dor: http://dx.doi.org/10.18601/01245996.v18n35.02. 
de otros actores, como las Bacrim y los grupos guerrilleros que aún siguen operando, incluido el ELN. Para entender los impedimentos que surgirán para implementar con éxito el acuerdo y los mecanismos que pueden frustrarlo es esencial entender los costos que enfrentarán estos actores como resultado de la paz. $\mathrm{El}$ marco temporal del análisis es de unos cinco años.

Aunque a los colombianos se les pide que perdonen muchas atrocidades de las FARC (Sengupta, 2016), y sean ambivalentes y estén insatisfechos por tener que hacer ese sacrificio de justicia y responsabilidad (así como se les pidió que perdonaran a los paramilitares en un acuerdo similar de 2005) $)^{1}$, el acuerdo de paz beneficia a muchos. El muy detallado acuerdo de casi trescientas páginas promete una enorme transformación social de la periferia rural largamente olvidada que haría mucho más equitativo el contrato social colombiano ${ }^{2}$. Esta reestructuración del contrato social hacia una mayor equidad y hacia la prometida transformación social está en el núcleo de la "paz" (o la renovación de la violencia) que Colombia obtendría con el acuerdo. Esta transformación es muy deseable, social y normativamente, pero es también muy costosa y compleja y se requerirán décadas para lograrla. Su ejecución no será fácil y está íntimamente entrelazada con los costos que enfrentarán algunos actores colombianos esenciales.

\section{LOS COSTOS MONETARIOS}

Gran parte de la discusión de los costos del acuerdo se ha centrado en los costos monetarios, en particular de la profunda reestructuración de las zonas rurales acordada. El gobierno colombiano no ha publicado sus estimaciones y solo lo hará si el plebiscito aprueba la paz. Se espera que los costos asciendan a varios puntos porcentuales del PIB durante muchos años. Algunos componentes de la transformación social pueden ser ya parte de los planes y expectativas presupuestales, lo que reduciría el monto total de los nuevos costos.

El “dividendo de la paz" (los beneficios económicos de la reducción de la violencia) podría disminuir aún más los costos totales, aunque la magnitud de este dividendo puede variar notablemente. Una parte importante de la reducción de los costos monetarios por dividendos de la paz a menudo está asociada a la disminución de las muertes en combates de guerra y homicidios relacionados (y no relacionados). En Colombia estas ya descendieron sustancialmente hace varios años.

\footnotetext{
1 Sobre las limitaciones de justicia y reparación de un acuerdo anterior con los paramilitares en 2006, ver, p. ej., ICG (2008).

2 Para una revisión del acuerdo, ver IGC (2016).
} 
Además, no todas las muertes en el conflicto han sido causadas por las FARC; muchas se pueden atribuir a otros grupos, como las bandas criminales. A diferencia de muchos gobiernos anteriores, el gobierno de Santos ha buscado diligentemente desmantelar esos grupos, como los Urabeños, uno de los más poderosos y destructivamente influyentes $^{3}$. No obstante, los Urabeños y otros grupos, como los Rastrojos y las Águilas Negras, persisten en todo el país, ejerciendo la violencia, la extorsión y la usurpación de fondos públicos, y manteniendo variados portafolios de economías ilícitas, como las drogas, la tala y la minería ilegales. En diversos grados, también buscan agresivamente influencia política.

Otro componente del dividendo monetario de la paz podría provenir de una reducción del gasto militar, aunque eso puede implicar grandes costos políticos, como se verá más adelante. Además, los componentes financieros de un dividendo de la paz suelen provenir de un aumento de la inversión extranjera directa (IED), algo que Colombia ha promovido activamente. Pero, de nuevo, gran parte del aumento de la IED ya se materializó, asociado ante todo al boom de productos básicos; y como sus precios han caído de manera sustancial, la IED en Colombia ha disminuido visiblemente (World Bank, 2015). De hecho, la expectativa general es que el gobierno tendrá que recortar su presupuesto ante la caída de precios de los productos básicos en un momento inoportuno, mientras que el acuerdo de paz demanda un enorme gasto nuevo durante muchos años.

La ayuda de Estados Unidos a Colombia en el nuevo marco Paz Colombia (Franco, 2016), que asciende a unos 450 millones de dólares (dedicada a DDR, cultivos alternativos y políticas antinarcóticos, incluidos la erradicación, el desminado y la reparación a las víctimas), cubrirá una parte muy pequeña de los costos monetarios que enfrentará el país ${ }^{4}$. Eso es apropiado: el Estado y la sociedad colombianos tendrán que acoger la transformación social que promete la paz y pagar por ella. Pero no será fácil. Y Estados Unidos debe asegurar que su ayuda no se consuma en esfuerzos antinarcóticos imprudentes, como la erradicación, que poco dejarían al desarrollo social y rural. Ciento cinco millones de dólares, hasta ahora casi la cuarta parte del paquete, se han asignado únicamente al desminado, un esfuerzo al que Noruega también hace una importante contribución. En contraste, entre los años fiscales 2000 y 2016, el Congreso de Estados Unidos asignó 10 mil millones de dólares al Plan Colombia y al seguimiento de sus programas (Beittel, 2016).

${ }^{3}$ Ver, p. ej., Gagne (2016a y 2016b).

${ }^{4}$ Para los detalles de la ayuda de Estados Unidos, ver Beittel (2016). 


\section{COSTOS POLÍTICOS Y DE OTROTIPO}

\section{LAS FARC}

Una causa de la ambivalencia de la sociedad colombiana respecto del acuerdo de paz es la impresión de que las FARC se benefician excesivamente. Es cierto que la dirigencia de las FARC parece haber logrado su objetivo de evitar el encarcelamiento, pero el futuro de mediano y largo plazo no parece color de rosa para las FARC. Aunque se permita que participen en política después de su conversión en partido político, su experiencia en funciones organizativas y administrativas normales es muy limitada. Sí, históricamente han obtenido legitimidad basada en resultados mediante una provisión mínima de bienes públicos -alcantarillado, recolección de basuras, clínicas y escuelas- en sus zonas de operación, financiada con ingresos del tráfico ilegal de drogas. Pero si las FARC transformadas desisten de participar en el aún floreciente tráfico de drogas en Colombia, quizá no tengan ingresos para tales dádivas económicas y para seguir compitiendo con el Estado en la provisión de tales bienes públicos. Las farc tienen poca experiencia o visión económica, empresarial y administrativa diferente de la anterior. Además, en la última década, la mayor parte de dicha legitimidad ha provenido principalmente de la protección a los cultivadores contra la erradicación de sus parcelas de coca. De nuevo, esta también disminuiría si ahora las FARC ayudaran a extender la presencia del Estado y reducir ese cultivo, aunque las modalidades de ese proceso, que se examinan más adelante, pueden ser muy complejas y proporcionar a las FARC algunas fuentes de legitimidad basada en resultados.

Es más posible, sin embargo, que las FARC intenten competir en elecciones libres, sin duda a nivel nacional pero incluso a nivel municipal. Sus mejores oportunidades de tener futuro político se encuentran en las zonas que controlan, en las 22 Zonas Veredales Transitorias de Normalización y en los seis campamentos más pequeños estipulados en el acuerdo, donde sus unidades residirán durante seis meses después de que este entre en vigor. Y aun así, gran parte de su influencia política futura puede provenir de la tradición, la narrativa y de medios claramente no democráticos, y no de la legitimidad basada en resultados.

Además de remodelar su papel como intermediario entre el gobierno y los cultivadores de coca, la mejor opción de las FARC para seguir siendo un actor político relevante podría ser su conversión en baluarte contra la extorsión y la usurpación de fondos públicos por parte de las Bacrim. Ese papel político, sin embargo, supone varias 
cosas: una, que frentes particulares no deserten y se unan a las Bacrim locales; dos, que el Estado colombiano sea capaz de proteger a los actores políticos y administrativos de las FARC de que sean asesinados e intimidados por las Bacrim más allá de la fase de DDR, de hecho, en los próximos años; y tres, que las FARC no adopten el mismo enfoque de "política mediante extorsión" que las Bacrim.

Un factor esencial que influirá en la calidad de la paz que se desarrolle en Colombia será la capacidad de las FARC para mantener el mando y un fuerte control sobre sus comandantes de nivel intermedio, no solo inmediatamente después de que el acuerdo entre en vigor, sino también durante los dos o tres años siguientes. Las FARC es un grupo armado fuertemente jerarquizado que no se ha dividido a pesar de los golpes repetidos contra su dirigencia, y a pesar de la fractura de otros grupos armados. Así, es menos probable que muchos de sus comandantes de nivel medio deserten y se conviertan en actores puramente criminales o en grupos armados encubiertos por una ideología reinventada, como ocurrió en el caso de la desmovilización de los paramilitares hace diez años. Además, durante una reciente conferencia de las FARC, sus líderes aprobaron por unanimidad el acuerdo de paz. Buscando presentar una faz aceptable para la sociedad y promover el voto afirmativo en el plebiscito, se comprometieron a dejar la guerra atrás y abrazar una segunda oportunidad en la política (AP, 2016).

Sendero Luminoso en Perú no era menos jerarquizado, y, sin embargo, dos de sus líderes -el camarada Artemio y el camarada Alipio- no solo se escindieron sino que mantuvieron la lucha militar contra el Estado y controlaron un amplio territorio, aunque remoto, como el distrito de Monzón, llegando a ser actores esenciales en la producción y el tráfico de drogas durante otras dos décadas ${ }^{5}$. No es claro qué tipo de incentivos mantendrán a los comandantes intermedios de las FARC apoyando el acuerdo de paz y operando dentro de sus restricciones. Si renuncian a participar en el tráfico de drogas, la mayoría probablemente no disfrutará los beneficios económicos de la paz ni una carrera política exitosa. Que se mantengan anclados en la paz dependerá en gran medida de la fortaleza de su lealtad y obediencia a la dirigencia y quizá de las comodidades de vivir en paz, en vez de ocultarse en las selvas y escapar a la persecución del ejército colombiano.

Otro caso revelador es el acuerdo de "paz" de 2009, en Nigeria, con el Movimiento por la Emancipación del Delta Nigeriano (MEnd). En esencia, el gobierno nigeriano cooptó a los dirigentes del MEND

${ }^{5}$ Ver, p. ej., Palmer y Bolívar (2011).

Revista de Economía Institucional, vol. i8, n.o 35 , segundo semestre/2oi6, pp. i3-38 
pagándoles y dejándoles controlar varias empresas, tanto legales como extorsivas, en sus zonas de influencia. Pero los altos dirigente del MEND no estaban dispuestos a compartir las rentas con sus comandantes de nivel medio, y ni los dirigentes del MEND ni el gobierno dedicaron recursos adecuados para DDR o cooptación pura de los 15 mil integrantes del MEND que se iban a desmovilizar (Aghedo, 2013). En tres años, la "paz" se marchitó gradualmente. Diversas formas de violencia y criminalidad retornaron al Delta, y surgieron nuevos grupos armados, como Vengadores del Delta del Níger. En junio y julio de 2016, los Vengadores del Delta del Níger y el MEND buscaban negociar un nuevo acuerdo de paz con el gobierno, aunque con pocas posibilidades de que, independientemente de un nuevo acuerdo formal, hubiese cambios sustantivos en el terreno ${ }^{6}$.

Y, por supuesto, en Colombia, muchos comandantes de nivel medio de las FARC, en particular cuando luchen económica y políticamente en la vida civil, con el tiempo enfrentarán grandes tentaciones de retornar a la táctica armada para obtener el control de actividades ilegales como el tráfico de drogas, la minería del oro, la tala ilegal y el robo de tierras incluso para cultivos legales. Las negociaciones del acuerdo de paz y sus perspectivas ya alteraron los equilibrios de poder y del tráfico de drogas entre los actores armados, incluidas las Bacrim y el ELN, con el que el gobierno no ha logrado hasta ahora negociaciones de paz significativas. Ambos grupos de actores han intentado entrar en territorio de las FARC y redoblarán sus esfuerzos una vez estas empiecen a entregar sus armas. Aunque grupos de narcotraficantes mexicanos, como el cartel de Sinaloa, han tenido presencia en Colombia durante casi una década, la producción y el contrabando de drogas dentro de sus fronteras están a cargo de actores colombianos. Es entonces posible que las redes de producción y tráfico establecidas puedan reconstituirse violentamente después del acuerdo de paz. Esa respuesta violenta ya está en marcha y estabilizar el mercado puede tomar mucho tiempo, incluso en términos de violencia. En algunas zonas, las unidades de las FARC que deserten podrían relevar, unirse o competir violentamente con el ELN, y no solo con las Bacrim.

El número de guerrilleros rasos de las FARC que sucumban a la violencia criminal organizada o se unan a otros grupos dependerá esencialmente de la calidad del DDR. Durante mucho tiempo el gobierno ha intentado resaltar la efectividad de su DDR de los grupos paramilitares y de desertores de las Farc. De hecho, y como es lógico, ese programa no era perfecto, la reincidencia sigue siendo un tema

${ }^{6}$ Ver, p. ej., Stratfor (2016) y Amaize et al. (2016).

Revista de Economía Institucional, vol. i8, N. ${ }^{\circ} 35$, segundo semestre/2oi6, Pp. I3-38 
importante y al menos la tercera parte de las Bacrim tuvo origen en grupos paramilitares (Gutiérrez y González, 2012). Entre los factores que impulsan esta reincidencia están el bajo nivel educativo de los ex combatientes y, por tanto, sus limitadas oportunidades económicas después del desarme, así como la presencia de grupos criminales en las inmediaciones (Kaplan y Nussio, 2016), es decir, de redes que facilitan la deserción y las oportunidades económicas ilegales. Ambos factores abundan en el caso del DDR de las FARC. Además, la decisión de realizar en bloque el DDR de los combatientes de las FARC, en vez de hacerlo en forma individual, como se hizo al menos formalmente en la práctica durante el proceso paramilitar, aumenta aún más la probabilidad de que los combatientes de las FARC no encuentren fácilmente oportunidades económicas adecuadas; otras características, como el alejamiento de la sociedad colombiana y la falta de experiencia, plantean otro reto. Muchos han vivido en la selva la mayoría de su vida y no tienen habilidades sociales o económicas. Pero en la selva su vida se entrelazaba con un sentimiento ideológico y de autoestima que no podrán recuperar después del DDR. Para muchos, la mejor oportunidad de empleo será como guardias de seguridad en almacenes y parqueaderos.

En la efectividad del DDR tendrán fuerte influencia otros factores. ¿Las comunidades locales estarán dispuestas a acoger a los ex combatientes?, ¿estos serán atacados por actores criminales, antiguos

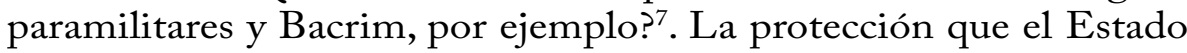
debe proporcionar a los ex combatientes de las FARC va más allá de la protección de sus unidades en los campamentos de desmovilización planeados y de las zonas de normalización durante 180 días. Las fuerzas policiales regulares tendrán que proporcionar esa protección en los años venideros, de ser necesario en forma individual. La reintegración de desertores de las FARC a menudo enfrentó el reto de que fueran expulsados de las zonas con fuerte pasado paramilitar y presencia de las Bacrim, como Medellín, o simplemente asesinados por ellos (Felbab, 2011a). A menudo la única protección que podían encontrar era unirse a un grupo armado o criminal.

En suma, durante un lapso de tres a cinco años, los ex combatientes y diversos comandantes de nivel medio y jefes de frente enfrentarán múltiples e intensas presiones para volver a la criminalidad o a la violencia políticamente encubierta.

7 Para una descripción de cómo influyen esos factores en la efectividad del DDR, en sus tasas históricas de efectividad y en sus desafíos, ver, p. ej., Muggah (2009), Felbab (2015a) y Torjese (2013). 


\section{El EJÉRCITO Y LA POLICÍA}

El ejército colombiano también enfrentará costos sustanciales como resultado de la paz. Un tema es el de los procedimientos de justicia y los castigos que afrontarán su cuerpo de oficiales y soldados individuales por atrocidades de guerra. En uno de los casos más notorios -el de los "falsos positivos" durante la década de 2000-, centenares y quizá más de mil personas inocentes fueron asesinadas por soldados que aducían que sus víctimas eran guerrilleros. No fueron casos de identificación equivocada durante la niebla de la guerra, ni mera consecuencia de que las fuerzas contrainsurgentes no pudieran distinguir entre guerrilleros y pobladores. Muchas de las víctimas fueron llevadas con engaño a lugares remotos, a menudo con promesas de empleo, asesinadas y vestidas de guerrilleros por los soldados, y por ello estos recibieron vacaciones y otras bonificaciones (Romero, 2008). Muchos oficiales superiores conocían el engaño y alentaron el asesinato. Los procesos por los "falsos positivos" han continuado durante años, antes del acuerdo de paz. Pero se pueden reabrir casos antiguos e inactivos.

Aparte de los procedimientos de justicia por crímenes del pasado, el ejército colombiano quizá enfrente grandes costos presupuestales como institución. Creció notablemente en términos de personal activo, equipo, capacidades y presupuesto en las últimas tres décadas. Por ejemplo, solo en términos de personal, se amplió en un tercio entre 2005 y 2015, de 207 mil soldados a 296 mil (IIss, 2006, 39; 2016, 389). Al cabo de algunos años de paz, la sociedad puede no estar dispuesta a seguir recaudando impuestos para apoyar a los militares, e incluso puede ser que no se cumpla con las pensiones y beneficios antes prometidos a los soldados. ¿Los veteranos con pensiones y beneficios reducidos estarán tentados a unirse a bandas criminales?

A diferencia de otros ejércitos de América Latina, el de Colombia no tiene una historia de golpes de Estado, y tal escenario sigue siendo muy improbable. Pero cabe imaginar que al menos algunos elementos del ejército den futuro apoyo tácito a políticos de derecha que intenten deshacer la paz legislativa o legalmente. Tales intentos de desbaratar, subvertir y derogar un acuerdo de paz con rebeldes armados se han emprendido repetida y exitosamente en Filipinas en su proceso de paz con el Frente Moro de Liberación Nacional (FMLN) durante la última década ${ }^{8}$.

\footnotetext{
${ }^{8}$ Entrevista de la autora con un negociador clave de los acuerdos de paz filipinos, Singapur, noviembre de 2015, y Bangkok, 2016. Ver también Plank (2015) y Coronel (2013).
}

Revista de Economía Institucional, vol. i8, n.o 35, Segundo semestre/2oi6, pP. I3-38 
Además de los costos presupuestales, es posible que cambie la postura de las fuerzas militares colombianas (Ellis, 2016). Se supone que el ejército se reorientará a la defensa externa a lo largo de las fronteras. Gran parte de su frontera es porosa y el ejército colombiano se enfocaría en esas zonas. En particular, la frontera con Venezuela, que facilita el tráfico de drogas y muchos tipos de contrabando, podría llegar a ser una gran fuente de inestabilidad si un colapso del régimen venezolano suscitara enormes flujos de refugiados a Colombia o, aún peor, si hubiese una guerra civil en Venezuela. Muchos de los grupos armados y criminales que todavía quedan en Colombia realizan operaciones en la frontera con Venezuela, y a veces controlan de facto partes de ella. Impulsar la presencia del Estado en esas zonas y limitar las operaciones de estos grupos son la prioridad correcta para el gobierno colombiano. Pero llevar a cabo esa tarea será un desafío.

Para reducir la incomodidad de la reducción del ejército y del recorte potencial de los beneficios prometidos a los soldados, el gobierno también está explorando oportunidades de mantenimiento de la paz en el extranjero. Estados Unidos y Colombia han intentado promover oportunidades para asesores militares y oficiales de inteligencia colombianos en América Central y México, pero han encontrado cierta renuencia de los gobiernos y ejércitos de esos países a aceptar funciones destacadas o sustanciales de los militares colombianos. Además, así aumentara la aceptación, el empleo y las oportunidades presupuestales para los militares colombianos seguirían siendo limitados.

E1 mantenimiento de la paz promete conservar nómina a muchos soldados más y mejorar el prestigio institucional internacional del ejército colombiano. Ya existe la expectativa de que soldados colombianos se desplieguen en el Congo. El ejército de Nepal usó con éxito el mantenimiento de la paz para compensar los costos de la paz con los maoístas después de 2006 y logró integrar al menos 1.500 ex combatientes maoístas en sus filas ${ }^{9}$. Los nepaleses también sobresalen en el mantenimiento de la paz en comparación con otros países que contribuyen a tales esfuerzos. En África, como en la República Centroafricana, hay gran necesidad de mantener la paz. En Somalia, la fuerza de contrainsurgencia y mantenimiento de la paz de la Unión Africana, Amisom, combate con dificultades a los activistas islamistas radicales de Al Shabab (Felbab, 2015b y 2016). Las habilidades de contrainsurgencia y otras capacidades militares que las fuerzas colombianas podrían aportar al contexto africano son de mucha utilidad. No obstante, el entorno humano en el Congo o

\footnotetext{
${ }^{9}$ Sharma (2013); ver también Bogati (2015) e ICG (2011).
} 
Somalia en nada se parece al que las Fuerzas Armadas colombianas están acostumbradas a encontrar, y las complejidades políticas del mantenimiento de la paz o, más precisamente, de la contrainsurgencia y el combate activos, son enormes.

La policía colombiana también ha crecido: de 121 mil integrantes en 2005 a 159 mil en 2015 (IIss, 2006, 33 I; 20 I 6, 39 I). Para ampliar la presencia del Estado, desarrollar la periferia largamente olvidada y suprimir la criminalidad se requiere el firme cumplimiento de la ley, la estrategia, la doctrina y los protocolos correctos, así como desarrollar capacidades y profesionalizar a la policía. Las cifras por sí solas no son suficientes, pero tienen importancia. La existencia de un gran número de policías corruptos y abusivos puede poner en peligro la paz y el desarrollo y acentuar la fragilidad, así como la violencia y el resurgimiento de la criminalidad. Pero una escasa presencia de policías efectivos es igualmente problemática. De hecho, aunque en todos los municipios colombianos haya habido alguna presencia de la policía durante una década, ese despliegue policial es a veces muy pequeño. Por tanto, la policía colombiana no puede enfrentar las mismas presiones para reducir el tamaño que el ejército. Puede haber, por el contrario, necesidad de aumentar más su tamaño.

Una posibilidad es reentrenar y reenganchar el exceso de soldados colombianos como policías. Este enfoque aliviaría los costos de la reducción del ejército y no es raro en América Latina. En gran parte de la región, en particular en México y América Central, el ejército se ha desplegado regularmente para cumplir fines de policía, y se han trasladado o recontratado soldados y comandantes en la fuerza policial. Pero este enfoque tiene graves desventajas. Las habilidades de la policía, en particular las necesarias para tener buenas relaciones con las comunidades locales y para suprimir el crimen organizado, como la vigilancia de criminales y puntos candentes, son muy diferentes de las habilidades militares. La diferencia más básica es que los policías deben estar capacitados para utilizar la mínima fuerza posible y solo como último recurso, mientras que a los soldados se les suele adiestrar para destruir al enemigo con fuerza letal desde el comienzo.

Para desarrollar relaciones positivas con las comunidades locales y legitimarse, la policía colombiana debería hacer el esfuerzo de reclutar localmente, entre comunidades con mínima o inexistente presencia de la fuerza policial, entre militares afro-colombianos y entre ex combatientes y simpatizantes de las FARC que aprueben rigurosos programas de selección y capacitación. 
De hecho, las unidades rurales de la fuerza policial en particular tendrán que reorientarse hacia la política de acercamiento y protección de la comunidad y alejarse de la mentalidad de contrainsurgencia paramilitar de facto. Las fuerzas urbanas intentaron esa transformación hace varios años. En 2010 se adoptó el Plan Nacional de Vigilancia por Cuadrantes, comúnmente llamado "Plan Cuadrantes", construido en torno a la política de acercamiento a la comunidad para corregir las deficiencias y pautas anteriores de comportamiento abusivo en lugares como Medellín. El programa hace énfasis en el despliegue permanente de unidades en las comunidades, asigna a los agentes de policía la tarea de conocer a la comunidad y ordena que estén presentes en una zona particular durante un buen tiempo antes de ser trasladados a otra zona. Al comienzo, las evaluaciones parecían muy positivas, pero con el tiempo han variado fuertemente ${ }^{10}$. La evaluación de la Fundación Ideas para la Paz en noviembre de 2012, por ejemplo, estimó una reducción del 18\% en homicidios, del 11\% en asaltos personales y del $22 \%$ en robo de vehículos (FIP, 2012). Pero estudios posteriores son más críticos. Cómo Vamos, una entidad de investigación que mide indicadores de calidad de vida en las principales ciudades de Colombia y del exterior, clasificó a Bogotá en un triste penúltimo lugar a escala nacional en percepción de seguridad; solo el 21\% de los residentes se sentían seguros en la ciudad (Cómo Vamos, 2013). E1 Centro de Estudio y Análisis en Convivencia y Seguridad Ciudadana encontró en 2014 que un $71 \%$ de los encuestados en Bogotá estaba "muy insatisfecho" o "insatisfecho" con la policía. $\mathrm{Su}$ informe también calculó que los homicidios aumentaron en la capital entre 2013 y 2014 (CEACsc, 2014). Estas variadas evaluaciones no necesariamente significan que la estrategia y la conceptualización sean inválidas: la percepción ciudadana de la policía y la seguridad y las estadísticas de delitos varían por muchas razones. Pero sí implican que se requieren mejoras adicionales en el enfoque y el diseño para localidades específicas. Más en general, revelan que la vigilancia de la paz requerirá numerosos cambios y adaptaciones para que el cumplimiento de la ley no sea lo que solía ser durante la guerra civil y la contrainsurgencia.

La vigilancia de la paz también requerirá una rendición de cuentas y un control civil robustos. Así, tiene sentido trasladar la policía del Ministerio de Defensa, adonde hoy pertenece, al Ministerio del Interior u otra dependencia, pero separada de las fuerza militares. Pero más allá de este cambio institucional, también es necesario construir

${ }^{10}$ Para una excelente recopilación de las diversas evaluaciones, ver León (2015). 
y alentar sistemáticamente juntas de ciudadanos-policía en ciudades y zonas rurales como mecanismos para la legitimidad y la rendición de cuentas de la policía así como para identificar problemas y formular estrategias.

\section{LOS POLÍTICOS DE DERECHA, LAS ÉLITES Y LOS INTERESES CREADOS}

E1 ex presidente Álvaro Uribe (quien ocupó el cargo entre 2002 y 2010) ha hecho una intensa campaña para evitar y subvertir el proceso de paz con las FARC. Los castigos a las FARC en los que ha insistido, como el encarcelamiento, serían una capitulación que las FARC no aceptarían; el ejército colombiano no la ha conseguido porque requeriría la derrota total de las FARC en todo el país, y el gobierno aún no está cerca de lograrla. Sin embargo, Uribe y los políticos de derecha que lo rodean, como las élites rurales y otros intereses creados, no abandonarán simplemente su empeño de sabotear el proceso de paz, incluso si se aprobara el plebiscito y el acuerdo de paz entrara en vigor. Podrían intentar seguir el ejemplo de las fuerzas de derecha filipinas que han recurrido repetidamente a demandas judiciales y legislativas para descarrilar los acuerdos de paz con el FMLN. Durante varios años ha habido intercambios políticos y de contrainsurgencia entre Colombia y Filipinas, y Colombia ha intentado exportar su desmovilización de los grupos paramilitares como modelo de desmovilización para Filipinas.

Con mucha más facilidad, los políticos de derecha y los intereses creados simplemente podrían socavar desde dentro la implementación del desarrollo rural. Una profunda transformación rural como la que promete el acuerdo reduciría el desproporcionado poder económico y político que aún mantienen las élites rurales y la impunidad con la que pueden actuar tan a menudo. Incluso la historia reciente del país está repleta de ejemplos de dicha dinámica. Durante el último lapso del gobierno de Uribe y comienzos del gobierno de Juan Manuel Santos, sus ministerios competentes - como el de Agricultura- fueron un gran obstáculo para el Plan Nacional de Consolidación Territorial, la fase de construcción de la contrainsurgencia que buscaba llevar una presencia multifacética y robusta del Estado y el desarrollo a zonas donde supuestamente no había presencia de las FARC ${ }^{11}$. Se marchitaron, entonces, el Plan de Consolidación y esfuerzos similares, incluso sus componentes emblemáticos, como el de la región de la Macarena (Neuman, 2015). Los decepcionantes resultados se debieron en parte a falta de recursos, pero más a menudo y significativamente, a

${ }^{11}$ Ver, p. ej., Felbab (2011b) e Isacson (2012).

Revista de Economía Institucional, vol. i8, N. ${ }^{\circ} 35$, segundo semestre/2oi6, Pp. I3-38 
que los ministerios eran reacios o incapaces de implementarlos de manera eficaz. Los intereses creados lograron reformar las políticas que buscaban beneficiar a la población marginada en beneficio de ellos mismos ${ }^{12}$. De hecho, una de las razones para que el gobierno de Santos desviara su enfoque y sus energías a la negociación de una paz con las FARC fue la paralización total del Plan de Consolidación y del desarrollo rural en los ministerios y en el campo.

Pero incluso si se pudiera incentivar a los ministerios competentes para que ejecuten con diligencia los esquemas de construcción de Estado y de desarrollo rural y superen los graves problemas de coordinación que anteriormente socavaron los esfuerzos de consolidación, ¿la administración municipal podrá funcionar como socio del Estado en la implementación? La inyección de recursos a las administraciones municipales será esencial, pero también puede crear incentivos para que los grupos criminales y los actores armados intenten extorsionar y hurtar los recursos para el desarrollo, como ha ocurrido repetidamente en Colombia. E1 Estado colombiano necesitará entonces organizar una protección más efectiva de los alcaldes y administraciones locales de la que ha logrado históricamente. Una función política creativa de las FARC podría ser supervisar y revelar la presión de los grupos ilegales o los intereses creados y de las agro-empresas para evitar ese robo de recursos.

Paradójicamente, el fin de la violencia formal con las FARC y el aumento del valor de tierra y de los recursos naturales en zonas antes disputadas o inaccesibles podrían desatar nuevas formas de violencia, robo de tierras, desalojo y desplazamiento. Esa ya ha sido la dinámica en Colombia durante algunos años, donde nuevas formas de intimidación y desplazamiento de poblaciones locales han logrado el control de tierras para cultivar palma africana, talar bosques, extraer carbón e incluso para ecoturismo, como en el Parque Tayrona (ibíd.; ver Bocarejo y Ojeda, 2016). De hecho, tan solo en el año pasado fue desplazada la asombrosa cantidad de 200 mil personas debido al nuevo robo de tierras, prolongando la violencia criminal y política, y el tráfico de drogas (Miroff, 2016). El acuerdo de paz promete devolver la tierra robada a los desplazados, unos 7 millones en total, o darles nuevas tierras en otras zonas. El gobierno colombiano espera utilizar satélites espaciales y otras soluciones técnicas, así como las memorias históricas expresadas a través de mapas comunales de

12 Entrevistas con funcionarios colombianos involucrados en el Plan de Consolidación, funcionarios de usaid y de la embajada de Estados Unidos, expertos en desarrollo y seguridad y actores de desarrollo local, Bogotá, Nariño, Catatumbo y Magdalena Medio, 2009, 2011, y 2015. 
tierras, para crear catastros y entregar títulos. Pero esos esfuerzos de restitución de tierras han estado en marcha durante la mayor parte del gobierno de Santos, y han avanzado con mucha lentitud. En realidad se han devuelto muchas menos tierras de las que se esperaban en 2010. Además, muchos desplazados no quieren volver a las zonas rurales aunque breguen económicamente en los barrios marginales que rodean las grandes ciudades del país. Si bien, en el mediano plazo, puede ser económicamente más viable proporcionarles paquetes de ayuda económica, capacitación técnica y otros tipos de ayuda que tratar de que vuelvan a las zonas rurales; tales esfuerzos enfocados en lo urbano también son muy costosos en el corto plazo.

\section{LOS CULTIVADORES DE COCA}

Entre los muchos demandantes de los beneficios de la paz en Colombia están los cultivadores de coca. En el acuerdo de paz, las FARC se comprometen a trabajar para terminar el tráfico de drogas y el gobierno se compromete con el desarrollo rural que proporcionaría oportunidades económicas viables en la economía legal a esos cultivadores. Después de rechazar las protestas cocaleras contra la erradicación, el gobierno de Santos detuvo la fumigación aérea de los cultivos, para usar únicamente la erradicación manual ${ }^{13}$. Durante mucho tiempo la fumigación aérea ha sido sumamente polémica a nivel político y ha proporcionado a las FARC gran capital político entre los cultivadores de coca (Felbab, 2010). Durante muchos años Colombia fue el único país que utilizó la fumigación aérea.

Pero aun en medio de las protestas políticas contra la erradicación, y de la incertidumbre política sobre el proceso de paz, el cultivo de coca ha aumentado visiblemente. Según el Departamento de Estado de Estados Unidos, se incrementó en un 39\%, de 80.500 ha en 2013 a 112.000 ha en 2014 (usds, 2016). Ni Estados Unidos ni la Oficina de Naciones Unidas contra la Droga y el Delito (onUdD) han publicado datos del cultivo de coca en Colombia en 2015, pero la expectativa general es que no disminuyó y que quizá sea mayor que en 2014. Esto no es sorprendente; nunca se han abordado las causas subyacentes al cultivo de coca, incluida la marginación de sus cultivadores, y el cultivo ha fluctuado en el país, pues durante años se ha desplazado entre Colombia, Perú y Bolivia según varían las condiciones del mercado, los niveles de supresión y otros factores, como la enfermedad del cultivo.

\footnotetext{
${ }_{13}$ Para información de las marchas cocaleras que promovieron el cambio de política y la posición reciente de las FARC ante el movimiento cocalero, ver Brodzinsky (2013). Ver también Felbab y Newby (2015).
}

Revista de Economía Institucional, vol. i8, n.o 35, Segundo semestre/2oi6, pP. I3-38 
Proporcionar medios de vida alternativos eficaces a los centenares de miles de cultivadores de coca, y a otros más que podrían tomar su lugar, será muy difícil, requerirá enormes recursos y no tardará años sino décadas. En los años noventa, países como Birmania, Laos y Vietnam lograron erradicar los cultivos de drogas ilegales a una escala similar mediante una combinación de represión, erradicación e incentivos económicos limitados negociados a los agricultores, aunque en Birmania eso no duró y el cultivo de amapola volvió a aumentar (Felbab, 2015 c y Windle, 2016). La China de Mao Zedong erradicó la amapola en la década de 1950 a una escala aún mayor, sin proporcionar casi ningún medio de vida alternativo, en un ambiente de total temor y sin resistencia política a un régimen que no se abstuvo de ejecutar a millones de personas ${ }^{14}$. Solo un país ha tenido éxito en la eliminación total del cultivo de drogas ilegales mediante medios de vida alternativos: Tailandia. Allí se necesitaron tres décadas de esfuerzos, mucha experimentación y ajuste de los medios de vida alternativos, y un gran compromiso político y financiero de la familia real tailandesa y de los socios externos, incluida la ayuda financiera sostenida durante largo tiempo. Fundamentalmente, durante los años clave de esos esfuerzos, en los años ochenta y noventa, Tailandia fue uno de los tigres asiáticos y todo el país creció de un modo que generó muchos nuevos empleos. En el pico del cultivo de amapola en los sesenta, la producción total era inferior a $20 \mathrm{mil}$ ha, una pequeña fracción de lo que se debe afrontar en Colombia. Los medios de vida alternativos se diseñaron como un desarrollo rural integral y multifacético y no se centraron simplemente en la sustitución de cultivos ${ }^{15}$. Buscaban extender los derechos de ciudadanía a los cultivadores de amapola, y proporcionarles oportunidades educativas y servicios de salud. La erradicación fue negociada, y tardó varios años para llevarse a cabo (a menudo cinco o más), después de que los esfuerzos de medios de vida alternativos llegaran a los pueblos y solo después de que empezaran a producir ingresos.

Sería conveniente que Colombia estudiara cuidadosamente el modelo tailandés. Y Estados Unidos debe tener paciencia y no perjudicar la profundización del proceso de paz insistiendo en una erradicación prematura de la coca. Un problema clave en los esfuerzos para proporcionar medios de vida alternativos en Colombia, a menudo agravado erróneamente por Estados Unidos, ha sido insistir en la erradicación de la coca como precondición de la ayuda económica o demasiado

\footnotetext{
${ }^{14}$ Ver, p. ej. Slack (2001), Yongming (1999) y Yung-fa (1995).

15 Ver, p. ej. Renard (2001) y Felbab (2014).
} 
pronto, tres o seis meses después de que lleguen unos "medios de vida alternativos" muy inadecuados. Esta ayuda inicial nunca ha sido suficiente para estimular medios de vida adecuados y sostenibles, y en su mayoría son paliativos contra la inseguridad alimenticia debida a la erradicación o pérdida del cultivo de coca. En la última década el gobierno de Barack Obama y el Congreso de Estados Unidos han mostrado una prudente paciencia con el cultivo de amapola en Afganistán. Es hora de aplicar un aprendizaje y una prudencia semejantes a las políticas antinarcóticos en Colombia, incluidos sus problemas de largo plazo y sus efectos contraproducentes, como el de la erradicación prematura ${ }^{16}$.

La realidad es que en Colombia habrá mucha coca durante largo tiempo, muy posiblemente en niveles bastante mayores que en los últimos años. Pero si, debido en parte a la presión de Estados Unidos, se pasa a la erradicación forzada antes de tener medios de vida alternativos, se correrá el riesgo de perjudicar la transformación rural que puede ser el ancla profunda de la paz en ese país.

Aunque en septiembre de 2016 Estados Unidos descertificó de nuevo a Bolivia, por noveno año consecutivo, por lo que considera un incumplimiento de los esfuerzos antinarcóticos, el modelo boliviano de un cato es otra estrategia que merece explorarse y considerarse en Colombia ${ }^{17}$. Bajo la política de un cato se permite que una familia cultive coca en una pequeña porción de tierra -un cato, unos 12,35 $\mathrm{m}^{2}$ - para garantizar la seguridad alimentaria y la supervivencia económica básica de la familia, mientras que los medios de vida alternativos y los esfuerzos de erradicación buscan disminuir el cultivo de áreas mayores que un cato y reducir gradualmente tanto la pobreza como la dependencia de ese cultivo (Youngers, 2013; Farthing y Ledebur, 2014).

El gobierno de Evo Morales ha sido diligente en la erradicación de la coca excedentaria, a menudo destruyendo casi un tercio del cultivo anual. El nivel real de cultivo es discutible: según las últimas cifras de Estados Unidos, aumentó en un 30\% entre 2013 y 2014, a 35.000 ha (USDS, 20I6). Según la onUDD y el gobierno boliviano, se redujo de 20.400 ha en 2014 (un tercio menos de lo que estimó el gobierno de Estados Unidos) a 20.200 ha en 2015 (onudD, 2015; Bonello, 2016). Pero incluso con las estimaciones más altas de Estados Unidos, la producción de coca en Bolivia sigue siendo mucho más baja

${ }^{16}$ Para la efectividad y las limitaciones de los efectos antinarcóticos en Colombia y Afganistán, ver Felbab (2010 y 2015d).

17 Sobre el proceso de descertificación y sus problemas, ver, p. ej., New York Times (2016) y Ledebur y Romani (2016). 
que en Colombia o Perú. Es discutible que los niveles de cultivo en Bolivia sean el resultado del diseño de política y su ejecución efectiva o consecuencia de factores exógenos (desplazados por el aumento de cultivos en Perú y Colombia). Los funcionarios antinarcóticos de Estados Unidos sostienen que en la última década Bolivia volvió a ser un importante centro de reenvío de cocaína y lugar de reunión favorito y centro financiero de narcotraficantes colombianos y brasileños, y que buena parte del cultivo termina siendo desviada al narcotráfico ${ }^{18}$. El gobierno de Bolivia lo niega, y persigue a los traficantes.

La política del gobierno de Morales acerca de la coca también ha tenido problemas y se podría decir que ha fracasado en su segundo pilar básico: la "racionalización" de la coca, el empeño por encontrar salidas legales a los productos de la coca. En parte, debido a un entorno legal internacional desfavorable, pero también a falta de interés de los clientes; productos como el vino o el jabón de coca no han despegado. Para crear salidas legales al volumen de coca que excede a la cantidad que consumen los mercados bolivianos tradicionales (té y hojas para masticar), el gobierno ha recurrido a productos de harina de coca para alimentar a los niños que van a la escuela. Pero no les gustan porque la harina de coca es muy amarga.

El papel más productivo para las FARC y que podría asegurarles algún futuro político sería que apoyen medios de vida alternativos inteligentes y se opongan a la erradicación prematura mientras se retiran simultáneamente del comercio ilegal de cocaína.

El gobierno colombiano está dedicando mucho empeño al cultivo legal de marihuana para mercados medicinales externos e internos futuros como componente clave de sus esfuerzos de medios de vida alternativos. Ya concedió varias licencias para cultivar marihuana medicinal (The Economist, 2016). Pero a menos que muchos otros aspectos del desarrollo rural -incluidos la distribución y titulación de tierras, el acceso a microcrédito, el desarrollo de capacidades técnicas y de comercialización, y el apoyo para establecer cadenas de valor agregado y acceder a los mercados- también acompañen el impulso de la marihuana medicinal, esta padecerá los mismos y numerosos problemas de la sustitución por café, cacao o papa (Felbat et al., 2009). Además, sin apoyo especial, los pequeños cultivadores de marihuana medicinal no podrán competir con las grandes empresas agrícolas así como no pueden competir en otros cultivos legales. Se necesitará generar empleos e ingresos no agrícolas como componente esencial del empeño para reducir el cultivo de coca, de los esfuerzos para re-

${ }^{18}$ Entrevistas de la autora con agentes de la DEA, Washington DC, otoño de 2011. 
ducir la pobreza urbana y proporcionar ayuda a los desplazados. Y si el cultivo de marihuana medicinal legalizado despega de modo que pueda emplear más de un pequeño número de cultivadores de coca, su precio podría descender drásticamente a niveles que no proporcionen ingresos suficientes a los cultivadores pequeños.

Así, en muchas zonas donde hoy se cultiva coca, la marihuana medicinal no podrá competir con la cocaína. De hecho, debido a los costos de transporte desde esas regiones remotas, separadas de la infraestructura del país y de los mercados externos por selvas y cordilleras, solo es económicamente viable la producción de drogas ilegales de bajo peso y alto margen de ganancias, como la cocaína o la heroína. En la mayoría de esas zonas -con la posible excepción de los nichos de ecoturismo, como el avistamiento de aves que se podría desarrollar con el tiempo- ningún esfuerzo de medios de vida alternativos será viable: allí los cultivadores de coca solo podrán participar en economías legales y escapar de la trampa de la ilegalidad si se trasladan a otras partes del país. Pero hay otras zonas donde hoy se cultivan coca y amapola que se pueden desarrollar económicamente -bien sea con agricultura legal, minería legal u otras industrias-, y el gobierno colombiano y la ayuda internacional a los esfuerzos contra la droga se deberían concentrar en ellas.

Infortunadamente, la actividad sustituta más probable y viable para muchos cultivadores de coca puede ser la tala ilegal. Esa tala problemática -legal e ilegal, pero en todo caso insostenible y ambientalmente devastadora- surgió como sustituto de la amapola en Tailandia, Birmania, Laos y Vietnam (ver, p. ej. Felbab, 2015c). La tala ilegal aumentó significativamente en Colombia durante la última década, impulsada por la demanda internacional de maderas duras y el desmonte ilegal de tierras para cultivar palma africana. Y, por supuesto, los esfuerzos de erradicación anteriores empujaron a los cultivadores de coca a los parques nacionales y otras zonas boscosas, poniendo en peligro el entorno natural. Paradójicamente, podría ocurrir que la biodiversidad y el medio ambiente paguen un gran precio por la paz de Colombia. La preservación de esta abundante biodiversidad y la limitación del cambio climático son razones adicionales para que Estados Unidos no insista en una erradicación prematura equivocada del cultivo de drogas, y el gobierno colombiano debe oponerse a tales presiones hasta que pueda proporcionar medios de vida legales viables y deseables. Los costos ambientales no ameritan las bajas ganancias de la erradicación. 


\section{LA CLASE MEDIA Y EL CONTRATO SOCIAL}

A menos que Colombia logre llevar a cabo una reforma tributaria políticamente complicada, una parte grande y desproporcionada de los gastos financieros para apoyar la paz y el desarrollo y la transformación social prometidos recaerá sobre la clase media en las próximas décadas. Y está por ver por cuánto tiempo la clase media -muy vulnerable a los sufrimientos resultantes de choques macroeconómicos, a caídas de precios de productos básicos y a efectos tales como la mala salud de las cabezas de familia- esté dispuesta a soportar tal redistribución de los recursos. En Río de Janeiro, la disposición de la clase media a pagar por el desarrollo de las favelas marginadas con alta incidencia de la criminalidad se evaporó al cabo de tres años, a pesar del entusiasmo inicial por el esfuerzo y el amplio apoyo al llamado esfuerzo de pacificación (que también ha tropezado contra muchos otros obstáculos además de la falta de recursos adecuados $)^{19}$. En India, las clases medias han sido incluso menos generosas con los pobres -así hayan dejado de ser pobres apenas hace una generación o aún menos-, a menudo boicoteando los esfuerzos del gobierno para extender los servicios públicos y el desarrollo urbano a barrios marginales de las ciudades o zonas rurales subdesarrolladas (Prakash, 2014 y Chaplin, 1999 y 2011).

De hecho, tanto en aras de la sostenibilidad como de la equidad básica, la sociedad y el Estado colombianos deben tratar de implementar una reforma tributaria más equitativa. Pocos ricos deberían poder evadir el pago de impuestos o pagar impuestos inapropiadamente pequeños. Un elemento crucial es mantener el impuesto a la riqueza que desde la época de Uribe ha financiado el esfuerzo de guerra y convertirlo en un impuesto para apoyar el proceso de paz y el desarrollo de la periferia.

Además, la reforma tributaria también debe promover el crecimiento que crea empleo y no solo el capital -lo que significa replantear a fondo el sistema tributario arraigado desde hace décadas, que grava muy ligeramente la tierra (exacerbando el robo de tierras y la especulación) y fuertemente el trabajo, lo que privilegia el crecimiento intensivo en capital pero no la creación de empleo.

\section{CONCLUSIONES Y RECOMENDACIONES}

Si Colombia lograse dicha reforma tributaria sería un indicador de que puede alcanzar la paz sostenible con justicia social que promete

${ }^{19}$ Para los antecedentes y la efectividad del esfuerzo de pacificación conocido como UPP, ver, p. ej., Oosterbaan y van Wijk (2015). 
el acuerdo de paz con las FARc. Una paz más limitada y financiera y políticamente más barata, sin inclusión social ni equidad, puede ir a paso lento durante largo tiempo. Quizá -y tristemente- ese puede ser el resultado políticamente más probable cualquiera que sea el resultado del plebiscito sobre el acuerdo de paz con las FARC.

Pero ese futuro sería un terrible desperdicio de una oportunidad que puede no volver a presentarse durante largo tiempo. La periferia marginada subdesarrollada -en las zonas rurales remotas así como en las barriadas urbanas- se enconaría y quizá un día vertería de nuevo sus problemas sobre las partes desarrolladas y prósperas del país. En el más corto plazo, esa paz sin transformación social estaría impregnada de violencia criminal y social.

Colombia puede evitar ese mediocre resultado mediante varios mecanismos generales.

Perseguir la transformación de largo plazo. E1 gobierno de Santos debe seguir buscando activamente un amplio apoyo social para la transformación social ligada a la paz, más allá del “sî" en el plebiscito. Para conseguir ese apoyo, debería tratar de inmunizar a la nación contra los esfuerzos de los políticos de derecha y de los intereses creados para quebrantar la paz y la transformación social después de que termine su segundo mandato.

Impulsar la reforma tributaria. Santos debe tratar de llevar a buen término la reforma tributaria esbozada antes de terminar su gobierno, en especial si el plebiscito da un "sí" rotundo a la paz. El régimen también debería tratar de consagrar legislativamente el desarrollo social obligatorio de las zonas rurales y urbanas marginadas al menos durante una década. Puesto que será preciso poner a prueba muchos programas de desarrollo y construcción del Estado y a menudo alterarlos considerablemente para lograr mayor efectividad en el terreno, dicha legislación no debe entrar en los detalles de implementación. No debe especificar, por ejemplo, dónde, en qué y cómo se ha de gastar el dinero o asignar los fondos; basta indicar que se deben transferir recursos a comunidades y zonas marginadas para facilitar su desarrollo social y alcanzar una paz profunda. El espíritu de dicha legislación debe ser el de mantener la flexibilidad de la política al tiempo que se conserva un fuerte compromiso con la inclusión social y la equidad general. Instrumentalmente, el impuesto de paz se podría promover como un equivalente al impuesto de guerra a los ricos del gobierno de Uribe para apoyar el esfuerzo militar contra las FARC.

Bloquear y desalentar las deserciones. E1 gobierno colombiano y sus acompañantes internacionales deberían contrarrestar con prontitud 
las defecciones de los acuerdos de paz. Esta recomendación general incluye muchos elementos y facetas, como la persecución activa y la desactivación de las unidades de las FARC que se unan a otros grupos armados o criminales, así como un esfuerzo resuelto para proporcionar un DDR significativo, sólido y bien diseñado a los ex combatientes de las FARC y no una mera ayuda simbólica. La contundencia para aplastar las deserciones iniciales puede generar efectos disuasivos para impedir otras. También incluye el aumento de los esfuerzos contra las bandas criminales y el esfuerzo para atraer o debilitar militarmente al ELN y a otros grupos armados que proclaman objetivos políticos. Y lo más importante, incluye asimismo la protección contra los ataques físicos y el asesinato de líderes y combatientes de las FARC en los años venideros, más allá de los 180 días del desarme. También facilitaría la paz en el largo plazo prestar asistencia técnica y política a las FARC para que encuentren un papel legítimo y efectivo en el espacio político, quizá como vocero de los cultivadores de coca o de los pobres urbanos.

Secuenciar los esfuerzos de construcción de Estado y concentrar los recursos. Aunque el compromiso general del Estado y la sociedad ha de ser la construcción y el desarrollo del Estado en todo el país, se tendrá que secuenciar cómo y dónde se extiende y fortalece la presencia del Estado. La demanda de recursos para la construcción de Estado y su sólido desarrollo es demasiado alta para cubrir todo el país. Es políticamente muy difícil escoger qué zonas son estratégicamente más importantes y dónde se deben conseguir primero efectos demostración fundamentales para que se pueda mantener el compromiso con la transformación. Las elecciones democráticas presionan para que se dé a cada comunidad alguna dádiva, aunque esas dádivas limitadas no tengan efectos transformadores. De hecho, en la fase de construcción de la contrainsurgencia, desarrollo rural y esfuerzos para proporcionar medios de vida alternativos en Colombia se padeció este problema. E1 gobierno colombiano debería revisar las solicitudes de extensión de la presencia del Estado y destacar uno o dos policías en cada municipio, independientemente de cuántas decenas o centenares de kilómetros cuadrados cubra el municipio, o proporcionar a la comunidad un puente, un generador eléctrico o una clínica y nada más.

Pero no solo la política, también la justicia y la equidad dificultan la selección de unas pocas zonas como merecedoras de la inyección de ayuda estatal sólida, multifacética y amplia en la primera ronda mientras que otras deben esperar varios años para que les llegue un paquete similar. De hecho, en las diversas etapas del Plan de Consolidación hubo desacuerdos dentro del mismo gobierno y con las administra- 
ciones locales acerca de cuántas y qué zonas se debían seleccionar como zonas estratégicas y prioritarias. Esos debates terminaron sin resolverse, y el gobierno desvió la atención a las negociaciones con las FARC. Ahora tendrán que reanudarse.

Aunque la concentración de recursos y la secuenciación de las zonas de desarrollo del Estado son políticamente difíciles, son también necesarias. Eventualmente, todas las comunidades colombianas tendrán que ser cubiertas por el esfuerzo de desarrollo. Pero si el Estado empieza a hacer muy poco en todas partes, disipará sus recursos sin conseguir una transformación sostenible en la mayoría de las zonas y sin lograr apoyo político sostenible para los costos de la paz mediante efectos demostración creíbles.

\section{REFERENCIAS BIBLIOGRÁFICAS}

1. Aghedo, I. "Winning the war, losing the peace: Amnesty and the challenges of post-conflict peace-building in the Niger Delta, Nigeria", Journal of Asian and African Studies 48, 3, 2013, pp. 267-280.

2. Amaize, E.; N. Levinus y T. Nwankwo. "MEND, FG strike deal to end N-Delta crisis", The Vanguard (Nigeria), 31 de julio de 2016, [http://www.vanguardngr.com/2016/07/mend-fg-strike-deal-end-ndelta-crisis/].

3. AP. "Colombia's rebels unanimously approve peace accord with government”, The Associated Press, 23 de septiembre de 2016.

4. Beittel, J. "U.S. foreign assistance as Colombia's peace talks on the cusp of completion", Congressional Research Service, 20 de julio de 2016, [http://www.fas.org/sgp/crs/row/IN10454.pdf].

5. Bocarejo, D. y D. Ojeda. "Violence and conservation: Beyond unintended consequences and unfortunate coincidences", Geoforum 69, febrero de 2016, pp. 176-183.

6. Bogati, S. "Assessing inclusivity in post-war army integration process in Nepal”, IPS paper 11, CINEP, 2015, [http://ips-project.org/wp-content/ uploads/2015/11/IPSPaper11-Assessing-Inclusivity-in-the-Post-WarArmy-Integration-Process-in-Nepal_English.pdf].

7. Bonello, D. "un reports small decreases in Bolivia coca cultivation", InSight Crime, 6 de julio de 2016, [http://www.insightcrime.org/ news-analysis/bolivia-coca-cultivation-drops-closer-to-legal-cropallowance].

8. Brodzinsky, S. "Colombian rebels offer to support peasant protests", The Guardian, 23 de julio de 2013.

9. CeAcsc. "Primera encuesta: Felicidad y satisfacción de los ciudadanos en Bogotá D.C., año 2014", [http://www.ceacsc.gov.co/index.php/descargas1/ category/14-encuesta-de-felicidad-y-satisfaccion?download=8:encuestade-felicidad-y-satisfaccion].

10. Chaplin, S. "Cities, sewers, and poverty: India's politics of sanitation", Environment and Urbanization 11, 1, 1999, pp. 145-158. 
11. Chaplin, S. "Indian cities, sanitation, and the State: The politics of the failure to provide", Environment and Urbanization 23, 1, 2011, pp. 57-70.

12. Cómo Vamos. "Informe de calidad de vida 2013: Seguridad y convivencia ciudadana”, 2013, [https://s3.amazonaws.com/s3.documentcloud.org/ documents/1508082/22-ene-bcv-convivencia-seguridad-ciudadana.pdf].

13. Coronel F., M. Costly wars, elusive peace: Collected articles on the peace processes in the Philippines, 1990-2007, Ciudad Quezón, University of the Philippines Press, 2013.

14. Ellis, E. "Strategic insights: The post-conflict and the transformation of Colombia's armed forces”, Strategic Studies Institute, 17 de agosto de 2016.

15. Farthing, L. y K. Ledebur. "To the beat of a different drum: Bolivia's community coca control", NACLA Report on the Americas 47, 2, 2014, pp. 51-55.

16. Felbab-B, V. Shooting up: Counterinsurgency and the war on drugs, Washington DC, The Brookings Institution, 2010.

17. Felbab-B., V. "Reducing urban violence: Lessons from Medellín”, The Brookings Institution, 14 de febrero de 2011a, [http://www.brookings. edu/opinions/2011/0214_colombia_crime_felbabbrown.aspx].

18. Felbab-B., V. "Colombia's consolidation: Everything coming up orchids?”, The Brookings Institution, 8 de marzo de 2011b, [http:// www.brookings.edu/opinions/colombias-consolidation-everythingcoming-up-orchids/].

19. Felbab-B., V. "Improving supply side policies: Smarter eradication, interdiction, and alternative livelihoods and the possibility of licensing", LSE Drug Reform Series, 2014, [http://www.brookings.edu/ /media/ research/files/reports/2014/05/07\%20improving\%20supply\%20side\%20 policies\%20felbabbrown/improvingsupplysidepoliciesfelbabbrown.pdf].

20. Felbab-B., V. "DDR in the context of offensive military operations, counterterrorism, CVE and non-permissive environments: Key questions, challenges, and considerations”, J. Cockayne y S. O'Neil, eds., $U N D D R$ in an era of violent extremism: Is it fit for purpose?, Nueva York, United Nations University, 2015a, pp. 37-61.

21. Felbab-B., V. "Saving Somalia (again)", Foreign Affairs, 23 de junio de 2015b, [http://www.foreignaffairs.com/articles/somalia/2015-06-23/ saving-somalia-again].

22. Felbab-B., V. "Enabling war and peace: Drugs, logs, gems, and wildlife in Thailand and Burma", The Brookings Institution, East Asia Policy Paper No. 7, diciembre de 2015c, [http://www.brookings.edu/wpcontent/uploads/2016/07/Policy-paper-7-webv5-1.pdf].

23. Felbab-B, V. "No easy exit: Drugs and counternarcotics policies in Afghanistan”, The Brookings Institution, 29 de abril de 2015d, [http:// www.brookings.edu/wp-content/uploads/2016/07/FelbabBrownAfghanistan-final.pdf].

24. Felbab-B., V. "Somalia: Most-failed State", The Economist, 10 de septiembre de 2016.

25. Felbab-B, V. et al. "Assessment of the implementation of the United States Government's support for Plan Colombia's illicit crops 
reduction components", usAID, abril de 2009, [http://pdf.usaid.gov/ pdf_docs/PDACN233.pdf].

26. Felbab-B., B y A. Newby. "How to break free of the drugs-conflict nexus in Colombia", The Brookings Institution", 16 de diciembre de 2015.

27. Fip. "Impact evaluation of the National Plan for Community Policing in Quadrants", Fundación Ideas para la Paz, Report 18, noviembre de 2012, [http://archive.ideaspaz.org/images/Informe\%20Fip\%2018\%20 PNVCC\%20ingles_web-cristal.pdf].

28. Franco, D. "Paz Colombia': Santos, Obama announce next chapter of U.S. support", NBC News, 5 de febrero de 2016.

29. Gagne, D. "Colombia security forces failing to block Urabeños expansion”, InSight Crime, 11 de abril de 2016a, [http://www.insightcrime. org/news-briefs/colombia-security-forces-failing-to-block-expansionurabenos].

30. Gagne, D. “васкім: Winner or Loser in Colombia's Peace”, InSight Crime, 1 de julio de 2016b, [http://www.insightcrime.org/news-analysis/ bacrim-winner-or-loser-in-colombia-peace-deal].

31. Gutiérrez S., F. y A. González P. "Colombia's paramilitary DDR and its limits”, A. Giustozzi, ed., Post-conflict disarmament, demobilization and reintegration: Bringing state-buidling back in, Ashgate, Farnham, 2012.

32. ICG. "Correcting the course: Victims and the justice and peace law in Colombia”, International Crisis Group, Latin America Report 29, 30 de octubre de 2008, [http://d2071 andvip0wj.cloudfront.net/29-correcting-course-victims-and-the-justice-and-peace-law-in-colombia.pdf].

33. ICG. "Nepal's peace process: The endgame nears", Asia Briefing 131, 2011, [http://d2071andvip0wj.cloudfront.net/b131-nepal-s-peaceprocess-the-endgame-nears.pdf].

34. ICG. "Colombia's final steps to the end of war", International Crisis Group, 7 de septiembre de 2016, [http://d2071andvip0wj.cloudfront. net/058-colombia-s-final-steps-to-the-end-of-war.pdf].

35. IIss. The militar balance 2005-2006, International Institute for Strategic Studies, Londres, Routledge, 2006.

36. IIss. "Chapter eight: Latin America and the Caribbean", The Military Balance 116, 1, 2016.

37. Isacson, A. “Consolidating 'consolidation”, $W O L A$, diciembre de 2012, [http://www.wola.org/files/Consolidating_Consolidation.pdf].

38. Kaplan, O. y E. Nussio. "Explaining recidivism of ex-combatants in Colombia", Journal of Conflict Resolution, mayo de 2016, pp. 1-30.

39. Ledebur, K. y Y. J. Romani. "Some are more equal than others: U.S. decertification of Bolivia's drug control efforts", Andean Information Network, 21 de septiembre de 2016, [http://ain-bolivia.org/2016/09/ some-are-more-equal-than-others-u-s-decertification-of-bolivias-drugcontrol-efforts/].

40. León, K. S. “Colombia's national policing model: Real success?” AulA Blog, Center for Latin American and Latino Studies, American University, 2 de octubre de 2015, [http://aulablog.net/2015/10/02/ colombias-national-policing-model-real-success/]. 
41. Miroff, N. "Colombia's war has displaced 7 million. With peace, will they go home?", The Washington Post, 5 de septiembre de 2016.

42. Muggah, R. "Introduction: The emperor's clothes?”, R. Muggah, ed., Security and post-conflict reconstruction: Dealing with fighters in the aftermath of war, Abingdon, Routledge, 2009, pp. 1-29.

43. Neuman, W. "Push for Colombians to stop farming coca falls short", New York Times, 2 de junio de 2015.

44. New York Times. "How Bolivia fights the drug scourge", 14 de septiembre de 2016.

45. on udD. Estado Plurinacional de Bolivia: monitoreo de cultivos de coca 2014, agosto de 2015, [http://www.unodc.org/documents/bolivia/Informe_Monitoreo_Coca_2014/Bolivia_Informe_Monitoreo_Coca_2014.pdf].

46. Oosterbaan, S. y J. van Wijk. "Pacifying and integrating the favelas of Rio de Janeiro: An evaluation of the impact of the UPP Program on Favela Residents", International Journal of Comparative and Applied Criminal Justice 39, 3, 2015, pp. 179-198.

47. Palmer, D. S. y A. Bolívar, "Peru's Shining Path: Recent dynamics and future prospects", Florida International University, Western Hemisphere Security Analysis Center Paper 2, 2011, [http://digitalcommons.fiu. edu/cgi/viewcontent.cgi? article $=1001 \&$ context $=$ whemsac $]$.

48. Planck, F. "Not enough pieces of the cake? The Moro National Liberation Front (MNlF) in the Mindanao final agreement", Asian Security 11, 2, 2015.

49. Prakash, A. "The periurban water security problem: A case study of Hyderabad in Southern India”, Water Policy 16, 3, 2014, pp. 454-469.

50. Renard, R. D. Opium reduction in Thailand, 1970-2000: A thirty-year journey, Bangkok, undcP Silkworm Books, 2001.

51. Romero, S. "Colombia lists civilian killings in guerrilla toll", New York Times, 29 de octubre de 2008.

52. Sengupta, S. “Colombia's leader says peace deal rests on people's ability to forgive", New York Times, 19 de septiembre de 2016.

53. Sharma, G. "Ex-Maoist fighters join army in Nepal but challenges remain", Reuters, 26 de agosto de 2013.

54. Slack, E. R. Opium, State, and society: China's narco-economy and the Guomindang, 1924-1937, Honolulú, Hawai University Press, 2001.

55. Stratfor. "Nigeria's peace talks are doomed from the start", 17 de junio de 2016.

56. The Economist. "Cannabis in Colombia: Weeds of peace", 6 de agosto de 2016.

57. Torjesen, S. “Towards a theory of ex-combatant reintegration", Stability: International Journal of Security and Development 2 3, 2013, pp. 1-13.

58. usds. "International Narcotics Control Strategy Report (INCsR) - Colombia”, marzo de 2016, [http://www.state.gov/j/inl/rls/nrcrpt/2016/ vol1/253252.htm].

59. Windle, J. Suppressing illicit opium production: Successful interventions in Asia and the Middle East, Londres, I. B. Taurus, 2016.

60. World Bank. "Colombia country overview: Foreign direct investment, net inflows: 2005-2015”, 2015, [http://data.worldbank.org/indicator/ 
BX.KLT.DINV.CD.WD?end=2015\&locations $=$ CO\&start $=2005 \&$ vie $\mathrm{w}=$ chart.

61. Yongming, Z.Anti-drug Crusades in Twentieth-century China: Nationalism, history, and State-building, Lanham, Rowman y Littlefield, 1999.

62. Youngers, C. "Shifts in cultivation, usage put Bolivia's coca policy at the crossroads", World Politics Review, 5 de diciembre de 2013.

63. Yung-fa, C. "The blooming poppy under the Red Sun: The Yan'an way and the opium trade", T. Saich y H. van de Ven, eds., New perspectives on the Chinese Communist Revolution, Armonk, Sharpe, 1995, pp. 263-297. 